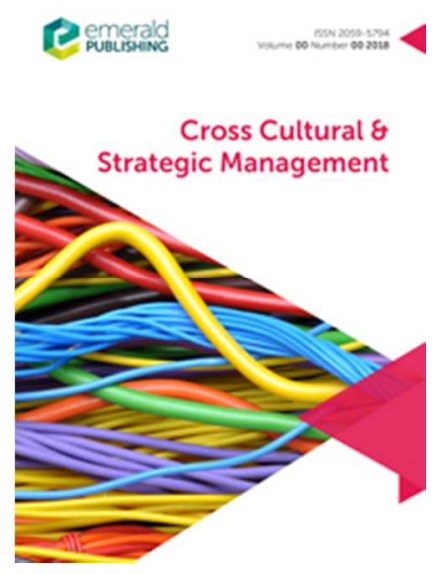

The role of Yin-Yang leadership and cosmopolitan followership in fostering employee commitment in China: a paradox perspective

\begin{tabular}{|r|l|}
\hline Journal: & Cross Cultural \& Strategic Management \\
\hline Manuscript ID & CCSM-12-2016-0216.R2 \\
\hline Manuscript Type: & Research Paper \\
\hline Keywords: & $\begin{array}{l}\text { Cosmopolitanism, Yin-Yang, Paradox, Cross-cultral leadership, Employee } \\
\text { commitment, China }\end{array}$ \\
\hline \multicolumn{2}{|l}{} \\
\hline
\end{tabular}

SCHOLARONE $^{\text {m }}$

Manuscripts 


\title{
The role of Yin-Yang leadership and cosmopolitan followership in fostering employee commitment in China: a paradox perspective
}

\begin{abstract}
Purpose - Utilizing a paradox perspective, this paper investigates the leadership-followership dynamic in foreign firms in China, specifically, the extent to which Yin-Yang leadership behaviors of Japanese expatriates and cosmopolitanism of Chinese employees influence employee commitment.
\end{abstract}

Design/methodology/approach - Data was collected through an online survey of Chinese employees who directly report to a Japanese supervisor in a Japanese subsidiary in China. Based on responses from 97 Chinese employees in three Japanese subsidiaries in China, we test if their cosmopolitan orientation and perceived Yin-Yang leadership behaviors of Japanese supervisors are related to employee commitment.

Findings - Yin-Yang leadership and cosmopolitan followership have a positive effect on employee commitment. Further, cosmopolitanism moderates the link between Yin-Yang leadership and employee commitment such that the follower's cosmopolitanism compensates for lower levels of Yin-Yang leadership, especially a relative lack of Yin leadership behaviors.

Research limitations/implications- Results suggest that Yin-Yang leadership and cosmopolitan followership work together as a two-way street of cultural adaptability to build employee commitment, highlighting the interplay between leadership and followership in multinational enterprises. Future research should attempt to further refine the Yin-Yang leadership construct, and to gain a larger sample representing multiple expatriate nationalities to corroborate the relationships found in this study. 
Originality/value -Our study applies a context-based approach to developing culturally-relevant leadership, through analyzing both the emic and etic concepts of culture in China. In so doing we extend the application of paradox theories to the cross-cultural leadership literature utilizing the Yin-Yang principle, which is particularly relevant in societal contexts where rapid and dramatic change brings to the fore competing values, needs and employee preferences.

Keywords Yin-Yang, Cosmopolitanism, Paradox, Cross-cultural leadership, Employee commitment, China, Japan

Paper type Research paper 


\section{Introduction}

The cross-cultural and expatriate leadership literature relies heavily on cultural value differences between societies in the investigation of cross-cultural challenges (Stahl, Miska, Lee and Sully de Luque, 2017; Stahl and Tung, 2015). The predominant approach is through assessing the scores of cultural dimensions (e.g., those from Hofstede and the GLOBE), where differences in cultural values, or cultural distance (Kogut and Singh, 1988) between societies are thought to affect cross-cultural leadership effectiveness (Dickson et al., 2003; Mendenhall et al., 2008; Wang et al., 2012). While leadership studies adopting the cultural values approach have generated many valuable insights in the cross-cultural management and international business fields, there is increasing awareness that cross-cultural studies should also be approached from perspectives other than differences in societal cultural values (e.g., Beugelsdijk, Kostova and Roth, 2017; Kirkman, Lowe and Gibson, 2006; Leung and Morris, 2015; Tung and Verbeke, 2010).

Recently, a paradox lens (Lewis, 2000) has been used in the theorization of leadership (e.g., Kan and Parry, 2004; Lavine, 2014; Zhang, Waldman, Han and Li, 2015). A paradox perspective highlights the tensions, contradictions and dualities in a given phenomenon such as leadership (for a comprehensive review of the application of paradox theories in the management field, see Shad, Lewis, Raisch and Smith, 2016). For example, paradoxical leadership (Lavine, 2014) focuses on the leader's ability to exhibit contradictory behaviors as necessary while still retaining integrity and credibility. In the same vein, paradoxical leader behaviors (Zhang et al., 2015) are those that simultaneously address the seemingly conflicting needs of followers as well as the often contradictory demands from the business and management environment. We propose that a paradox perspective is particularly relevant for theorizing cross-cultural leadership and 
followership, since operating in the global arena has become increasingly complex in nature.

Such complexity is characterized by the frequent need to balance seemingly opposite values, needs and preferences arising from different cultural contexts (Hofstede, 1980; House, Hanges, Javidan, Dorfman and Gupta, 2004; Inglehart and Baker, 2000; Schwartz, 1999, 2014), cognitive schemas (Leung and Morris, 2015) and thinking styles (Lee, 2017).

We adopt a paradox lens and argue that cross-cultural leadership and followership is a two-way street whereby both leaders and followers have to be skilled in dealing with complexity, ambiguity and possible contradictions inherent in cross-cultural relations within a multinational enterprise (MNE). Positive cross-cultural relations between local employees and expatriate managers have many important implications in local subsidiaries including employee commitment. Employee commitment is an affective attachment to the organization apart from purely instrumental worth (Buchanan, 1974; Meyer and Allen, 1997), and involves employee identification with organizational values and goals, a willingness to invest personal effort for the sake of the organization, and a desire to remain a member of the organization (Cook and Wall, 1980). Local employees' psychological attachment to, or feeling part of, the foreign firm is important to the operation of a MNE (Reade, 2001; Taylor et al, 2008), since employee commitment is associated with enhanced employee performance and willingness to embrace change in complex operating environments (Meyer et al., 2007; Taylor et al., 2008).

The challenge of employee commitment is evident in contemporary China, the country context for our study. While China has garnered the international spotlight as an attractive investment destination, and is currently the $3^{\text {rd }}$ largest FDI recipient in the world after the US and UK (WIR, 2017), it has been identified as the most challenging emerging market for the operation of MNEs (e.g., Mercer HR and Mobility Challenges of Emerging Markets, 2011. A 
major challenge is the relatively high turnover of employees, and retaining those particularly with technical skills and managerial potential (Nie, 2015). Such high rates of employee turnover, and hence low levels of employee commitment, is related to the fast-paced changes taking place in the Chinese institutional environment, particularly labor market reforms.

Labor market reforms over the past two decades in China have significantly changed the employment relationship, especially in the private sector (Gallagher, 2011; Taylor, 2005). A fixed-period contract has become the norm, and employees are prone to dismissal by employers (Witt, 2010). Once unemployed, individuals cannot receive social welfare benefits such as healthcare (Gallagher et al., 2011), and are thus exposed to considerable risks. It has been observed that strong pressure for survival in the labor market engenders self-interested goals which coexist in an apparent paradox with the family-oriented nature of Chinese collectivism (Faure and Fang, 2008). Such pressure for survival and the impact on employee behavior and expectations has also been observed in the subsidiaries of foreign firms. Lee and colleagues (2013), for example, found that Chinese employees working in subsidiaries of Japanese MNEs favor clear individual roles, short-term objective goals, clear criteria for promotion, a clear link between pay and performance, and frequent performance appraisals. This underscores the desire by Chinese employees to be highly marketable so as to progress and succeed in an uncertain marketplace where employment is on short-term contracts.

We propose that building employee commitment to the foreign subsidiary in China requires both appropriate leadership characteristics on the part of expatriate managers and followership characteristics on the part of local employees. A positive interpersonal relationship with supervisors is said to be the key to secure employee commitment in China (Chew and Putti, 1995; Yeh, 1988). Foreign managers thus need to demonstrate their reliability, trustworthiness 
and attractiveness by exhibiting culturally-relevant leadership behaviors that build relationships and respond to the expectations of Chinese employees. Whereas traditional cross-cultural leadership theories focus on cultural value differences between the HQ country and local subsidiaries of the MNE, we shift the focus to the local context, that is, from an etic to an emic frame of reference. This allows researchers to delve more deeply into the specifics of local culture that may not be captured by etic measures of cultural values. A local focus further allows researchers to utilize an indigenous perspective in the theorization of cross-cultural leadership that may help to explain leadership behaviors beyond theories developed in "the West," especially if the local context differs greatly from Western societies (Barkema, Chen, George, Luo and Tsui, 2015; Chen, 2016). We propose the Yin-Yang principle for building theory on cross-cultural leadership in China. Yin-Yang embodies an indigenous East Asian view of paradox and a holistic balancing approach to manage contradictions. This will be explained in detail in the following section.

On the followership side, there is increasing awareness in the literature that the follower's role and characteristics are critical but under-investigated in the leadership process (Kelley, 2008; Uhl-Bien et al., 2014). We propose that an important aspect of followership is cosmopolitanism, an individual's cultural openness and ability to transcend local cultural boundaries (Lee, 2015). While a foreign firm may be an attractive choice for career advancement and challenging jobs (Newburry, Gardberg and Belkin, 2006), work practices may be incompatible with the valued Chinese way of life (Fan and Zigang, 2004; Wu, Huang, Li and Liu, 2012; Xing, 1995). It is important, therefore, for employees to be comfortable with foreign cultures and a different work environment. In particular, the leadership style of foreign supervisors may contradict local practices, and may even include a mix of behaviors from the 
home country together with behaviors adapted to the host country, projecting in the eyes of followers an inconsistent leadership style. Cosmopolitanism thus enables followers to adjust to unfamiliar foreign practices, and to embrace leadership styles that may appear inconsistent or paradoxical.

The purpose of this study is to empirically investigate whether culturally-relevant YinYang leadership behaviors adopted by expatriate managers, together with local employees' cosmopolitanism, help to build employee commitment to foreign subsidiaries. Our study is set in multiple Japanese subsidiaries operating in China. The fact that China and Japan share a Confucian heritage and are often considered culturally similar may provide a modicum of control when examining culturally-relevant leadership in China. Our study makes two distinct contributions. First, it contributes to the literature on cross-cultural leadership in China by introducing a Yin-Yang balancing and paradox perspective as a fresh lens. We develop the concept of Yin-Yang leadership and propose it as a profile of culturally-relevant leadership behaviors in the contemporary Chinese context. Second, it contributes to building cross-cultural leadership theory by highlighting follower capabilities that embrace cultural unfamiliarity and possible contradictions or paradoxes in leadership behaviors of expatriate managers in foreign firms.

The paper proceeds with sections on Yin-Yang leadership and cosmopolitan followership as a basis for hypothesis development. This is followed by research methods, results, and discussion of the implications for research and practice.

\section{Yin-Yang Leadership}

Contingency theories of leadership state that the most appropriate leadership approach is 
dependent on context (e.g., Vroom and Jago, 1988). That is, managers can improve employee attitudes and performance by exhibiting an appropriate leadership style that is suitable to a given context (Rad and Yarmohammadian, 2006). In the cross-cultural management literature, it is often argued that the ideal leadership style in a particular context is highly contingent on national culture (Dorfman et al., 1997; House, 1971; Javidan et al., 2006; Larson et al., 1974). For instance, knowledge of cultural dimensions and leadership behaviors expected by members of a given society can inform managers how to adapt their style (Javidan et al., 2006). The implication is that expatriates need to adopt leadership behaviors that are relevant to the host country's local culture, in order to maximize the effective leadership of local employees (Dickson et al., 2003; House et al., 1999).

What the contingency theories of leadership do not address, however, are paradoxes (e.g., Smets et al., 2015), and the increasing need to embrace seeming opposites simultaneously (Lavine, 2014; Smith and Lewis, 2011; Zhang et al., 2015). Contingency theories have their roots in Greek philosophical traditions that, while concerned with contradictions, focused on opposites independently to surface underlying truths (e.g., Schad et al., 2016). Early contingency theory (e.g., Lawrence and Lorsch, 1967) examined "how contexts influence the effectiveness of opposing alternatives" (Smith and Lewis, 2011: 381). Such 'either/or' approach, that focuses independently on one alternative over another, has limitations, particularly in managing the complexities inherent in globalization. This has given rise to paradox theories (e.g., Lavine, 2014; Smith and Lewis, 2011) that consider the need for more holistic approaches to managing the tensions between seeming paradoxes that are contradictory yet interdependent, such as the organizational tensions between collaboration and competition, between global integration and local responsiveness, and between short-term profit and long-term success (e.g., Smith, Lewis 
and Tushman, 2016). Scholars have noted that the ability to manage such tensions or paradoxes contributes to greater leadership effectiveness (Faure and Fang, 2008; Lavine, 2014; Zhang et al., 2015).

A number of writers have offered the concept of Yin-Yang as an indigenous Chinese perspective on managing paradox that is relevant to cross-cultural management (Chen, 2016; Fang, 2012; Faure and Fang, 2008; Li, 2016; Luo and Zheng, 2016; Tung, 2008). Li (2012, 2014, 2016) has extended the work on paradox theory by introducing 'Yin-Yang balancing' (Keller and Lewis, 2016) which will be discussed below. In this age of globalization, people from different cultures are increasingly coming together; moreover, "culture in action is full of paradoxes, diversity and change" (Fang, 2012: 35). We believe that the concept of Yin-Yang offers an approach to leadership that transcends the limitations of contingency approaches and is relevant to the Chinese context, and beyond. Below we introduce the Yin-Yang principle as a basis for our proposed Yin and Yang leadership behaviors, and Yin-Yang balancing (Li, 2012, 2014, 2016) that completes our concept of Yin-Yang leadership.

\section{The Yin-Yang Principle}

An aspect of Chinese culture that foreign managers often find confusing is the Yin-Yang principle that manifests in dualities in cultural values (Faure and Fang, 2008). The Yin-Yang principle refers to an ancient Daoist philosophy in China that views all universal phenomena as being created by dual cosmic energies called Yin and Yang (Fang and Faure, 2011). The nature of Yin (阴) is represented by the moon, while the nature of Yang (阳) is represented by the sun (Chen, 2008). Yin has come to symbolize darkness, passivity, and femininity, whereas Yang has come to symbolize light, activity, and masculinity (Fang, 2012; Faure and Fang, 2008; Lee, Han, 
Byron, and Fan, 2008). The cultural manifestations of these dualities have come to the fore with globalization and the rapidly changing economic and institutional landscape in China (Fang, 2012; Faure and Fang, 2008). For instance, China is known for its traditional values of caring, face saving, harmony, and family and group orientation associated with collectivism. Yet the pressures for modernization have highlighted opposite values of individualism, self-expression and directness. We suggest that values such as caring and harmony are imbued with the qualities of Yin, and values such as self-expression and directness have Yang qualities.

While these values appear to be contradictory or paradoxical in nature, they coexist in contemporary China (Fang, 2012). This can be explained by the notion of 'seed', a further aspect of the Yin-Yang principle that will be discussed below. A seed of Yin resides in Yang, and a seed of Yang resides in Yin to produce a dynamic, holistic and ever-changing reality (Li, 2016). This suggests, for instance, that there is no light without dark, no strength without weakness (Faure and Fang, 2008). Thus, the Yin-Yang principle offers a holistic means for managing paradox, by embodying duality, unity-in-diversity, change and harmony (Chen, 2002), and provides an approach to leadership that is flexible and culturally relevant in China. Indeed, it has been noted that in China and other East Asian countries individuals have a cognitive style that embraces contradictions as being opposed but connected, and capable of coexisting in harmony (Lee, 2017; Wang et al., 2012). When expatriate managers consider which leadership behaviors to adopt in the Chinese context, they need to keep in mind the Yin-Yang principle and the general acceptance of paradox. The Daoist Yin-Yang perspective advises, for instance, that "leaders should be similarly gentle and soft, but also persistent and powerful" (Lee et al., 2008: 93).

We propose that to be successful in China an expatriate leader needs to flexibly embrace 
contradictions as a natural phenomenon and be prepared to exhibit what we refer to as Yin-Yang leadership. Consistent with the Daoist Yin-Yang perspective, and drawing on Lee et al. (2008), we conceptualize Yin-Yang leadership as comprised of Yin and Yang leadership behaviors. Yin leadership behaviors, imbued with feminine cosmic energy, prioritize a 'gentle and soft' approach (Lee et al., 2008). Yang leadership behaviors, imbued with masculine cosmic energy, prioritize a 'persistent and powerful' approach (Lee et al., 2008). While Yin and Yang leadership behaviors together constitute Yin-Yang leadership, we believe it is useful to consider the characteristics of the two constituent components in order to fully appreciate the whole. As the Yin-Yang principle provides a new opportunity for research and theory development in the field of cross-cultural leadership, we need to carefully consider what leadership behaviors represent Yin and Yang.

In conceptualizing Yin-Yang leadership and the underlying behaviors that represent Yin and Yang, we adopt a two-step process, namely, translation and contextualization. In the first, translation step, we draw from widely available, both traditional and contemporary, indigenous sources of Confucianism and Daoism, as well as the comparative studies based on the Hofstede and the GLOBE studies that discuss Chinese values and practices. Based on these readings, we 'translate' the prominent etic and emic cultural aspects of Chinese society into a list of culturally-relevant leader behaviors in China. Many studies highlight practices associated with collectivism (e.g., Redding and Ng, 1982; Warner, 2009; Wu, et al., 2012; Zhu et al., 2007) such as exhibiting care, maintaining harmony, saving face, networking, and prioritizing group over individuals in achieving goals and objectives, which are better known and in line with traditional Chinese values. We also identified perhaps lesser known aspects of Chinese society that tap into the notion of managing unprecedented risk and uncertainty in contemporary China (e.g., Lee et 
al., 2008; Lee, et al., 2013; Littrell, 2002 ) such as controlling, dominating, actively managing uncertainty, and effectively influencing or persuading others to achieve organizational goals, which may appear contradictory to the traditional Chinese values.

In the second step, we analyzed the identified list and grouped the culturally-relevant behaviors into four themes of higher-order leadership behaviors: relationship building, benevolence, uncertainty management, and decisiveness. The former two higher-order leadership behaviors, relationship building and benevolence, are contextualized as the traditional values of collectivism and Confucianism that highlight a partiality for leaders with a caring and relationship focus. The latter two higher-order leadership behaviors of uncertainty management and decisiveness are contextualized within the contemporary Chinese context which is characterized by rapid economic growth, institutional change, and job insecurity, all of which create in individuals a preference for leaders who can help progress their careers. Accordingly, we conceptualize the culturally-relevant leadership profile containing seeming opposites in contemporary China as 'Yin-Yang leadership' to mean the extent to which leaders exhibit a high level of both the Yin elements ('relationship building' and 'benevolence') and the Yang elements ('uncertainty management' and 'decisiveness') of leader behaviors. In the next sections we set forth our research hypotheses (depicted in Figure 1) by firstly providing in more detail our proposed leadership behaviors associated with Yin and Yang, and secondly by introducing YinYang balancing (Li, 2012, 2014, 2016) to complete our full concept of Yin-Yang leadership.

\section{Yin Leadership Behaviors}

We conceptualize Yin leadership behaviors as relationship building and benevolence, the two higher-order themes that we contextualize in accordance with the traditional Chinese values. 
Relationship Building. The first element of Yin leadership behaviors revolves around the indigenous Chinese concept of Guanxi. Guanxi is the Chinese term which means 'relation' or 'relationship' (Bian, 1994). This is the lifelong network of mutual relations involving reciprocal obligations among Chinese people, and is recognized as the source of dynamism in Chinese society (Wong et al., 2010). Guanxi is important in Chinese business because most Chinese people believe that they can reach their goals more effectively through interpersonal connections (Hwang, 1987). Underscoring the importance of interpersonal relationships in China, it is said that the value or importance of someone can be measured by observing his/her ties and relationships with others (Javidan et al., 2006). Guanxi is developed through social obligations (renquing) and giving and saving face (mianzi) (Redding and $\mathrm{Ng}, 1982$; Wong et al., 2010). Additionally, Wu (1994) added reciprocity as a key element in Chinese culture for developing and maintaining guanxi. The norm of reciprocity creates an obligation between people that sustains or strengthens the relationship. These elements are closely related to the interpersonal relationships among people in business and daily lives.

Fostering guanxi therefore requires a leader to maintain the organization built around close-knit ties, and the ability to maintain harmony. This might entail keeping the group working as a team, and settling inter-member conflicts (Stogdill, 1963). Maintaining guanxi, is associated with gaining trust from subordinates (Wu, 1996), which in turn is associated with higher employee commitment (Wong et al., 2010). This is important since Chinese society is a "low trust" society where people tend to trust only those related to them, in other words, to distrust those outside of the family or organization (Fukuyama, 1996). Therefore, it is important for managers in China to develop and maintain guanxi in their offices (Pearce and Robinson, 2000). 


\begin{abstract}
We propose that maintaining guanxi through relationship building is a culturally-relevant Yin leadership behavior, and will increase employee commitment to the organization.
\end{abstract}

Benevolence. The second element of Yin leadership behaviors revolves around consideration and care that a leader personally exhibits to subordinates. The nature of collectivism in China suggests that Chinese people appreciate a leader who is considerate (Bond and Hwang, 1986; Hui and Tan, 1996). Such a leader demonstrates benevolence and caring which builds trust in the leader and the perception of interactional justice among subordinates (Wu et al., 2012). It has been argued that the primary qualification of a leader in China is the ability to establish and nurture personal relationships (Javidan et al., 2006). In the study by Javidan et al. (2006), most Chinese workers revealed a preference for having a benevolent and sympathetic supervisor. Javidan et al. (2006) argue the importance of showing high respect to their employees and their family, and paying attention to designing work schedules and reward systems that show consideration and appreciation for their subordinates. A leader who is benevolent and considerate is likely to display characteristics of being approachable and friendly, being open about his or her actions, and treating group members with respect (Stogdill, 1963).

In sum, Yin leadership behaviors are captured by notions of relationship building and benevolence. We hypothesize as follows.

Hypothesis 1a. Yin leadership behaviors are likely to have a positive influence on Chinese employee commitment to the Japanese subsidiary.

\title{
Yang Leadership Behaviors
}


We conceptualize Yang leadership behaviors as uncertainty management and decisiveness, the two higher-order themes that we contextualize in accordance with a Chinese response to the rapid economic and institutional changes taking place in China.

Uncertainty Management. The first element of Yang leadership behaviors revolves around managing uncertainty and risk. Managing uncertainty and risk is important in a highly fluid economic and institutional environment. Particularly in the Chinese context, characterized by high uncertainty avoidance (Javidan et al, 2006; Littrell, 2002), the rapidly evolving economic and institutional changes have highlighted paradoxes in values around risk and uncertainty (Faure and Fang, 2008). Fan and Zigang (2004), for instance, categorized Chinese people's risk preference as 'risk-averse' due to the high uncertainty avoidance evident in their data. They found that Chinese managers tend to make careful decisions in the face of unpredictable situations, and to make immediate decisions only when they feel comfortable with the circumstances (Fan and Zigang, 2004).

However, there is a growing recognition among Chinese people that innovation for creating economic wealth in the current changing environment requires some amount of risk taking (Faure and Fang, 2008). Considering this, along with Chinese people's general preference for low risk, expatriate managers would be expected to work well under situations of uncertainty and to make careful decisions. This might entail predicting trends or events and anticipating problems and planning for them (Stogdill, 1963). The more accurately one can predict the success of a new product or venture, for instance, the greater the management of uncertainty and risk. We propose that uncertainty management is a culturally-relevant Yang leadership behavior, and can enhance employee commitment in the Chinese context. 
Decisiveness. The second element of Yang leadership behaviors revolves around taking initiatives and decisive action. Decisiveness is a leadership behavior that assertively moves people toward goals in a convincing way. This is valuable particularly in emerging economic and institutional conditions that have highlighted paradoxes in values around hierarchy and power distance (Faure and Fang, 2008). Xing (1995) points out that Confucian ideology is the social system which has governed most aspects of Chinese life throughout China's long history. The main characteristic of Confucianism is its hierarchical, authoritarian aspect which places emphasis on values such as conformity and respect for elders (Bond and Hwang,1986; Littrell, 2002). Hence, it is normal for Chinese people to consider differences in status as the best way to conduct interpersonal relationships, and it is therefore accepted and maintained at all levels of an organization's hierarchy (Bond, 1991).

Faure and Fang (2008) note, however, that while seniority continues to be maintained in society, it is also being challenged in recent times. There are more opportunities for younger people to take on responsible positions, and even to earn higher salaries than some of their seniors. Thus, leaders may increasingly need to rely, not on age-based seniority, for instance, but on other leadership qualities relevant to the changing economic environment to gain confidence from followers. Chinese people appreciate a leader who is able to take the initiative and to take decisive action (Lee et al., 2013; Littrell, 2002). In other words, there is respect for leaders who are authoritative, controlling and directive. This is likely to entail the ability to make convincing arguments and to assertively generate enthusiasm to reach a goal (Stogdill, 1963). We propose that decisiveness is a culturally-relevant Yang leadership behavior, and can serve to enhance employee commitment. 
In sum, managing uncertainty and risk in the fast-changing Chinese institutional and business environment requires an ability to assess future trends and to persuade subordinates and others to embark on a particular course of action. Thus, Yang leadership behaviors are those that help employees reduce uncertainty, and convey a decisive and convincing way of leading. We hypothesize as follows.

Hypothesis $1 \mathrm{~b}$. Yang leadership behaviors are likely to have a positive influence on Chinese employee commitment to the Japanese subsidiary.

\section{Balancing Yin and Yang: A Holistic Leadership Approach}

Li (2016) stresses the importance of balancing Yin and Yang as a way to manage paradox especially in complex environments. Li's $(2012,2014,2016)$ 'Yin-Yang balancing' emphasizes relativity, holism and change. This inherent dynamism is illustrated in Li's (2016: 59) depiction of the content and process of Yin-Yang balancing, whereby paradox is fully embraced "by truly accommodating and appreciating both trade-off and synergy between true opposite elements in the same place at the same time." In other words, the notion of balancing treats opposites as partially conflicting and partially complementary in an 'either/and' approach to paradox management. The premise is that 'either' indicates the existence of opposites while 'and' indicates the existence of unity. This differs fundamentally from the Aristotelian 'either/or' logic which fully separates opposites as a way to manage paradox (Jing and Van de Ven, 2016), and the Hegelian dialectical 'both/or' logic which temporarily accepts paradox. Li (2014: 322) makes a further distinction between 'both/and' logic and 'either/and' logic, in that the former "denies the possible coexistence of true opposites in the same place at the same time due to the assumed 
complementarity or synergy between 'fake' opposites." In essence, the 'either/and' logic inherent in Yin-Yang provides an approach that simultaneously embraces differences and similarities.

Following the 'either/and' logic, Yin and Yang leadership behaviors coexist as complementary opposites. As mentioned earlier, the seeds of opposites exist in each other; a seed of Yin exists in Yang, and a seed of Yang exists in Yin (Fang, 2012; Li, 2016). Li (2016: 59) brings out the importance of 'threshold' regarding the transition in the size of the seeds as critical for Yin-Yang balancing. In this process, opposites produce balance and harmony, a holistic whole, which highlights the dynamism inherent in the Yin-Yang principle. Faure and Fang (2008) have argued that Yin and Yang values are intertwined and both are important and meaningful in Chinese society and business, with one sometimes more salient than the other. Fang (2005-2006) brings this out in his 'ocean' analogy of culture, where some cultural values may rise to the surface at a given time while some remain dormant. This is underscored by Chen (2016) who states that the balance of any two opposites, such as Yin and Yang, depends on time and context. In the same way, it is reasonable to submit that environmental influences may determine the relative salience of Yin and Yang leadership behaviors over time.

Consistent with the dynamism inherent in the Yin-Yang principle, with the seeds of Yin and Yang each present and in motion within the other, we propose that Yin and Yang leadership behaviors interact to form Yin-Yang leadership. Yin-Yang leadership consists of a profile of leader behaviors, derived from the two-step process of translation and contextualization, that embrace and respond to opposites and dualities in Chinese culture. Thus we believe that a balance of leadership behaviors that respond simultaneously to the cultural needs of nurturing and building relationships while focusing on business development in a fast-paced, changing 
institutional environment will enhance employee commitment. We consider Yin-Yang leadership as a high level of both Yin and Yang leadership behaviors displayed by supervisors, and hypothesize as follows.

\author{
Hypothesis 1c. Yin-Yang leadership, or a high level of both Yin and Yang leadership \\ behaviors displayed by supervisors, is likely to have the greatest impact on Chinese \\ employee commitment to the Japanese subsidiary.
}

\title{
Cosmopolitan Followership
}

There is growing awareness in the leadership literature that the follower's role and characteristics are critical, but under-investigated, in the leadership process (Kelley, 2008; Uhl-Bien et al., 2014). Similarly, the cross-cultural and global leadership literature has identified key leadership capabilities, including being culturally relevant (Dorfman et al., 1997; House, 1971; Javidan et al., 2006), and managing contradictions and tensions (Zhang et al., 2015). While the role of the leader has been extensively discussed, the cross-cultural leadership literature has been surprisingly silent on the follower's role. We argue that followership plays an important role in cross-cultural contexts. In the case of Chinese employees who work in a foreign subsidiary of MNCs, the firm's routines and practices may not be culturally or organizationally compatible with the local Chinese context.

It is often challenging for expatriate managers to fully exhibit culturally-relevant leadership behaviors such as Yin and Yang leadership behaviors, as they may contradict their own accustomed leadership behaviors. Their leadership style may be perceived by followers to be inconsistent at times, as the leaders attempt to be culturally relevant but slip into their familiar 
leadership behaviors. It is therefore important for followers to have an open mind, and to transcend their own accustomed judgments, to embrace foreign expatriates' leadership behaviors which may not be familiar or always appear consistent. This includes the ability to make connections between seemingly inconsistent behaviors of their supervisor and to feel comfortable with contradictions, which largely originate from the efforts to deal with paradoxical demands from the business/management environment, but also come from the foreign supervisors' attempts to balance between their own familiar leadership style at home and their adjusted leadership style in the local Chinese context. Therefore, we further propose that cosmopolitanism, or cultural openness and transcendence of one's own culturally relevant assumptions (Lee, 2014), contributes to enhanced commitment of Chinese employees.

Cosmopolitanism refers to an individual's acquired disposition or identity horizon that transcends conventional local cultural boundaries (Lee, 2015), and is acquired through one's practice of exposing oneself to diverse products, places and people from different cultures in order to gain experience (Lee, 2014). Individuals who are high in cosmopolitanism are characterized by being curious and open to foreign cultures, enjoying interaction with foreigners, and even preferring diversity over homogeneity, since culturally diverse situations help them to constantly expand their identity horizon beyond what is culturally familiar (Lee, 2014). In the case of China, people have been increasingly exposed to different cultures through the entry of foreign MNEs since the Chinese government adopted its open-door policy in 1979. Due to this influx, many Chinese workers, especially those in regions where MNEs locate, are likely to have a crossvergent set of cultural values that meld their traditional Confucian culture with foreign cultures (Ralston et al., 1996; Lee, et al., 2013). We propose that Chinese workers who have high levels of cosmopolitanism are likely to be more open to new (and different) ways of running 
the firm, of managing employees, and of interacting socially within the foreign workplace which is likely to differ from the Chinese way, and accordingly hold positive attitudes toward their company. We hypothesize as follows.

Hypothesis 2. The higher the level of Chinese employees' cosmopolitanism, the higher their commitment to the Japanese subsidiary.

Further, we predict that cosmopolitanism may interact with Yin-Yang leadership to strengthen the predicted positive effect of Yin-Yang leadership on employee commitment (Hypothesis 1c). We submit that an employee with higher compared with lower levels of cosmopolitanism would be more open to a foreign supervisor's leadership behaviors that might appear paradoxical, for example, being caring while at the same time stern toward employees, or being considerate in eliciting the opinions of others yet ruthless in decision making. As followers with high levels of cosmopolitanism would more easily process and manage such seeming contradictions and inconsistencies, accordingly they are likely to better appreciate Yin-Yang leadership behaviors displayed by a foreign supervisor, thus contributing to positive attitudes toward the company. We hypothesize as follows.

\author{
Hypothesis 3. Employee cosmopolitanism will interact with Yin-Yang leadership \\ behaviors, such that Chinese employees' cosmopolitanism will heighten the proposed \\ positive relationship between Japanese supervisors' Yin-Yang leadership behaviors and \\ Chinese employee commitment to the Japanese subsidiary.
}


[Insert Figure 1 about here]

\section{Method}

\section{Sample}

The research sample was drawn from the Directory of Japanese firms in China 2011-2012 (The $21^{\text {st }}$ Century China Research Institution, 2011). All firms in the directory were contacted by email, regardless of industry and location within China in order to maximize the number of respondents.

Respondents were chosen according to the following selection criteria: 1) Chinese employees currently employed at a branch of a Japanese firm during the survey period; and 2) Chinese employees who reported to a Japanese supervisor. Several firms responded with the appropriate criteria, yielding a sample of 97 Chinese employees (female 52.27\%) from Japanese manufacturing and service firms in China. These include a stationery manufacturing firm, a Web-based apparel retailing firm, and a large consumer electronics manufacturing firm. Employee contact details were obtained from the participating firms, and the survey was launched online (via Qualtrics). The prospective respondents were asked to answer the questions on their own computers.

\section{Measures}

In designing the survey instrument, all questions were extracted from established scale inventories. The questions used in the survey were translated from English into Mandarin Chinese. We followed the recommended translation procedure in comparative business studies, 
using the translation and back-translation technique with two bilingual speakers who are fluent in both English and Mandarin Chinese.

Leadership Behaviors. We used several subscales of the 'Leader Behavior Description Questionnaire (LBDQ) - Form XII' scale, developed at the Fisher College of Business, Ohio State University (Stogdill, 1963) and is widely used among the leadership scholars. This scale is comprised of 12 subscales that comprehensively cover patterns of leader behavior. We selected four subscales-Integration, Consideration, Predictive Accuracy, Persuasiveness-that we assessed correspond most closely to the proposed Yin and Yang leadership behaviors. All items were measured on a 5-point Likert scale where $1=$ Always and 5=Never.

Yin Leadership Behaviors is conceptualized to include Relationship Building and Benevolence. Relationship Building is measured by three items from the Integration subscale. The Integration items assess the perception of respondents on the extent to which their supervisor is capable of maintaining a closely-knit organization, resolving inter-member conflicts, and keeping the group together as a team. Benevolence is tapped by three items from the Consideration subscale, and include approachability, friendliness, and respectfulness of the supervisor. Cronbach's alpha reliability for Yin leadership behaviors is .71.

Yang Leadership Behaviors is conceptualized to include Managing Uncertainty and Decisiveness. Managing Uncertainty is measured by three items from the Predictive Accuracy subscale, and assesses the perception of Chinese employees on the extent to which the supervisor makes accurate decisions and accurate forecasting of trends. Decisiveness is measured by three items from the Persuasiveness subscale and taps the extent to which the supervisor uses convincing arguments and inspires enthusiasm for a project. Cronbach's reliability alpha for Yang leadership behaviors is .72. 
Cosmopolitanism. To measure the cosmopolitanism of Chinese employees, we used seven items from the Cosmo-V10, a self-assessment scale developed by Lee (2014). Sample items include: 'I like interacting with people from countries other than my own country', and 'I am a citizen of the world.' All items were measured on a 5-point Likert scale where 1=Strongly Agree and 5=Strongly Disagree. Cronbach's alpha reliability is .83.

Employee Commitment. We used six items from the British Organizational Commitment Scale (Cook and Wall, 1980). Sample items include: 'I am proud to be able to tell people that I work for this company', and 'I feel myself to be part of this company.' All items were measured on a 5-point Likert scale where 1=Strongly Agree and 5=Strongly Disagree. Cronbach's alpha reliability is .78 .

Control variables. Gender and tenure (measured in years) are included as standard demographic control variables. In the context of Chinese-Japanese interpersonal interaction, we also included language proficiency as this would partly tap cultural familiarity, and could potentially affect the quality of interaction between supervisor and employee. Chinese employees' proficiency in the Japanese language and Japanese supervisors' proficiency in the Chinese language were measured on a scale from 1: No knowledge at all, to 6: Native speaker. In addition, we included job satisfaction (Agho, Price and Mueller, 1992) known to be the most robust and strongest predictor of employee commitment. Cronbach's alpha score for this scale is .72 .

\section{Results}

Table 1 shows the means, standard deviations and inter-correlations of the study variables. Table 2 presents the results of the multiple regression analyses which test our research hypotheses. We 
used hierarchical multiple regression analyses. In Model 1 we entered the control variables, including gender, tenure, employee's Japanese language proficiency, supervisor's Chinese language proficiency, and job satisfaction. In Model 2 we added our independent variables, Yin leadership behaviors, Yang leadership behaviors, and Cosmopolitanism. In Model 3 we added three 2-way interaction terms, beginning with our main variable Yin-Yang leadership (Yin leadership behaviors x Yang leadership behaviors). We also included two other 2-way interaction terms of Yin leadership behaviors x Cosmopolitanism and Yang leadership behaviors $\mathrm{x}$ Cosmopolitanism as it is necessary to include all possible combinations of 2-way interaction terms that comprise the 3-way interaction in Model 4. Finally, in Model 4 we added the 3-way interaction term of Yin leadership behaviors $\mathrm{x}$ Yang leadership behaviors $\mathrm{x}$ Cosmopolitanism to test our hypothesis 3, the interaction effect of Yin-Yang leadership and Cosmopolitanism on employee commitment. All of the interaction terms were calculated based on the standardized values of each component. The beta coefficients of the final model, Model 4, are used to determine support for the research hypotheses.

[Insert Tables 1 and 2 about here]

Our main hypothesis states a positive effect of Yin-Yang leadership on employee commitment (H1c). Additionally, we tested the separate independent effects of Yin leadership behaviors (H1a) and Yang leadership behaviors (H1b) on employee commitment. As shown in Table 2, Yin-Yang leadership shows a strong, positive relationship with employee commitment (beta=.39, $p<.01)$, thus supporting our hypothesis (H1c). Yin-Yang leadership, operationalized as a supervisor exhibiting high levels of both Yin and Yang leadership behaviors, captures Yin-Yang 
balancing or the dualities in leadership behaviors. Japanese supervisors who are perceived to exhibit high levels of both Yin and Yang leadership behaviors in a balanced manner are associated positively with Chinese employees' commitment to their firm.

We plotted the two-way interaction of Yin leadership behaviors and Yang leadership behaviors in Figure 2. As shown, greater degrees of Yin and Yang leadership behaviors are associated with the highest point of employee commitment (slope 1 in Figure 2). This further supports our hypothesis (H1c). Results in Figure 2 also indicate that when one component of Yin-Yang leadership is low, a higher level of the other component does not appear to help heighten employee commitment.

\section{[Insert Figure 2 about here]}

In terms of the separate, independent effects of Yin and Yang leadership behaviors on employee commitment, Yang leadership behaviors (Uncertainty Management and Decisiveness), appear to heighten Chinese employees' commitment to the Japanese subsidiary very strongly (beta $=.55, p<.001)$, supporting our hypothesis $(\mathrm{H} 1 \mathrm{~b})$. This suggests that Yang leadership behaviors contribute to employee commitment in addition to what is explained by Yin-Yang leadership, indicating that Yang leadership behaviors, on their own, positively contribute to Chinese employees' commitment to Japanese subsidiaries. By contrast, Yin leadership behaviors do not independently show a significant relationship with employee commitment (beta $=.10, \mathrm{n} . \mathrm{s}$.), and thus H1a is not supported. This indicates that Yin leadership behaviors only contribute to employee commitment if they are accompanied by Yang leadership behaviors (i.e., Yin-Yang leadership). 
We interpret these results in two possible ways. First, Yang leadership behaviors may be more prominent reflecting the contemporary expectation of Chinese employees' for career advancement in the current labor market context of rapid and dramatic change. Alternatively, this may be due to the specifics of our sample in that the supervisors are all Japanese. Japanese are known to be indirect and high context (Hall, 1976) in their communication and management style (Lee, et al., 2013), that is, low in Yang leadership behaviors. Thus, any exhibition of Yang leadership behaviors by Japanese supervisors will have a sharp, positive impact since the baseline of Yang leadership behaviors of Japanese supervisors can be considered to be relatively low.

Our second hypothesis (H2) states a positive effect of cosmopolitanism on employee commitment. Cosmopolitanism was found to be significantly and positively related to employee commitment (beta $=.25, p<.05$ ), supporting $\mathrm{H} 2$. Chinese employees who are more capable of transcending their narrow cultural boundaries, and who are more open to foreign cultures, people, norms and practices, show higher levels of commitment to the Japanese subsidiary. In terms of the moderating effect of cosmopolitanism on the relationship between Yin-Yang leadership and employee commitment (H3), the results show a strong negative effect on employee commitment (beta $=-.49, p<.001$ ). To understand the exact nature of the moderating effect of cosmopolitanism, we present the three-way interaction plots in Figure 3.

The data in Figure 3 reveal, first of all, that cosmopolitanism improves employee commitment rather dramatically when low Yin/high Yang leadership behaviors are in place (slope 3 in Figure 3). It also shows that cosmopolitanism improves employee commitment when high Yin/low Yang leadership behaviors are in place (slope 2), although far less dramatically than in the former case. This indicates that cosmopolitanism compensates for the lack of either 
Yin or Yang leadership behaviors, when they are not both at high levels, in gaining employee commitment.

Figure 3 shows that cosmopolitanism does not change the slope of the high Yin/high Yang leadership profile (slope 1) or the low Yin/low Yang leadership profile (slope 4), whereas it pulls up the scores of employee commitment for the high Yin/Low Yang and low Yin/high Yang profiles of Yin-Yang leadership when cosmopolitanism is higher, compared to when it is lower. More specifically, when Japanese supervisors display a high level of Yang leadership behaviors but a low level of Yin leadership behaviors, Chinese employees with a lower level of cosmopolitanism show weak commitment to the firm, whereas Chinese employees who are higher on cosmopolitanism show strong commitment to the firm (note the steep positive slope depicted in slope 3). A similar tendency, albeit much weaker, is shown for the high Yin/low Yang profile (note the gradual positive slope depicted in slope 2). Additionally, the figure confirms the following. First, high cosmopolitanism, compared with low cosmopolitanism is associated with higher employee commitment reported by Chinese employees in our sample, as per the cosmopolitanism main effect, H2. Second, the level of employee commitment is higher with Yang leadership behaviors (the score points associated with slopes 1 and 3), compared with Yin leadership behaviors (the score points associated with slopes 2 and 4), as per the Yang leadership behaviors main effect, H1b. Third, Yin-Yang leadership (slope 1: high Yin and high Yang) shows the highest score points for employee commitment, as per the Yin-Yang leadership interaction effect, H1c.

[Insert Figure 3 about here] 


\section{Discussion}

Traditional bipolar cultural frameworks (e.g., Hofstede's and the GLOBE's) that allocate national cultures from low to high along a few measurable cultural dimensions have intellectual roots in Aristotelian dualism or Western formal logic. Western epistemological systems that facilitate mental separation of complex, interrelated phenomena into simplified opposites of 'either/or,' and do not leave room for seeming opposites to coexist, have limitations particularly in the contemporary global business environment (Chen, 2008; Keller and Lewis, 2016; Lee, 2017; Li, 2016; Tung, 2008; Tung and Verbeke, 2010). The Eastern epistemology of the YinYang principle, however, which embraces paradox and dynamism (Keller and Lewis, 2016; Li, 2016), offers a more robust approach to managing complexity. Drawing on the paradox perspective and the Yin-Yang principle, (Faure and Fang, 2008; Li, 2012, 2014, 2016), we conceptualized 'Yin-Yang leadership' as leader behaviors derived from a two-step process of translation and contextualization that embrace and respond to these opposites and 'dualities' in Chinese culture, and proposed it as culturally-relevant leadership in contemporary China. We demonstrated in our sample that leadership behaviors that respond simultaneously to the cultural needs of nurturing and building relationships while focusing on business development in a fastpaced, changing institutional environment contribute to employee commitment. We also demonstrated that Chinese employees' cosmopolitanism, the follower side of paradox management, also contributes to employee commitment. Details of our contributions are outlined below.

First, we advance the cross-cultural leadership literature via a context-based approach to develop culturally-relevant leadership, Yin-Yang leadership in the Chinese context. Our two-step, "translation-contextualization" approach to theorizing cross-cultural leadership, by focussing on 
the cultural characteristics of the operating context rather than on the differences between the host country culture and the MNE headquarters country culture, allows researchers to delve deeper into the specificity of local culture. This includes combining the emic and etic approaches to Chinese culture, and incorporating Daoist thinking style and epistemology of Yin-Yang into the theorization of cross-cultural leadership. As noted by Fang (2012: 36), "the Yin Yang perspective of culture emphasizes the need to understand the intrinsic paradoxical nature of culture." Yin and Yang are opposites, yet are complementary and coexist (Fang and Faure, 2011; $\mathrm{Li}, 2016)$. This is evident in our results which show that employee commitment is highest when foreign supervisors display high levels of both Yin and Yang leadership behaviors, indicating that the leaders' ability to simultaneously exhibit seemingly opposite, paradoxical leadership behaviors is positively associated with employee commitment to local subsidiaries.

Further, our research revealed that Yang leadership behaviors appear to be more salient than Yin leadership behaviors, the traditional collectivist-oriented leadership behaviors, in gaining employee commitment. Yang Leadership behaviors were found to be a strong and independent predictor of employee commitment, suggesting that the Yang component of YinYang leadership such as forecasting trends, anticipating problems, and making accurate decisions are highly important to gain commitment from Chinese employees, particularly in a rapidly changing economic and institutional environment. These results illustrate the dynamic nature of Yin-Yang balancing (Faure and Fang, 2008; Li, 2016) such that, while both Yin and Yang exist, at any point in time one may rise to the surface and be more salient. Fang (2012: 39) has proposed that in any given culture human beings will select the values that are most relevant for a particular situation, context or time, promoting some and suppressing others, to create a "unique value configuration." Indeed, our results can be interpreted as "value trumping" (Osland 
and Bird, 2000) of the Yang component over the Yin component in contemporary China given the current economic and labor market climates that bring competition and career advancement to the fore.

The second contribution of our paper lies in highlighting the role of followership in crosscultural leadership. The follower's role and characteristics in the leadership process are increasingly recognized as critical but under-investigated (Kelley, 2008; Uhl-Bien et al., 2014). We identify and test cosmopolitan followership as an important factor in enhancing employee commitment to a foreign-owned company and, together with Yin-Yang leadership, managing paradox in complex operating environments. Cosmopolitanism, that is, a broadened identity horizon that transcends local cultural boundaries and embraces opposite values and practices, is on the rise in China. We reasoned that if an employee liked interacting with people of different cultures, and was open to considering that the values and norms of other cultures were as valid as, or perhaps even superior to, one's own, there would be a good chance that such a person could find satisfaction in working for a foreign firm, and commit to a foreign firm. The results show that cosmopolitanism indeed has a direct and positive relationship with employee commitment as we hypothesized. This suggests that Yin-Yang leadership and cosmopolitan followership work together as a 'two-way street' of cultural adaptability and openness that builds employee commitment. In addition to the direct positive impact, cosmopolitanism acts as a moderator to further strengthen the positive relationship between Yin-Yang leadership and employee commitment. More specifically, when there is an imbalance between Yin and Yang (high Yin/low Yang or low Yin/high Yang), cosmopolitanism appears to compensate for such imbalance vis-à-vis the effects on employee commitment. This implies that local employees' 
cosmopolitanism can act as a game changer when foreign supervisors' Yin and Yang are not in balance, underscoring the key role of followership in the cross-cultural leadership process.

Both of the above contributions advance our theorization of cross-cultural leadership and followership. We have used a more context-specific approach, Yin-Yang leadership and cosmopolitanism to delve more deeply into the cross-cultural leadership and employment relations challenges experienced by Japanese companies in China. This has allowed a more nuanced approach to cross-cultural leadership that cannot be gleaned from the traditional bipolar cultural frameworks. The literature suggests that there are cultural similarities between China and Japan given their shared Confucian cultural heritage (e.g., Gupta et al., 2002; Javidan et al., 2006). While cultural distance (Kogut and Singh 1988) is generally portrayed as an obstacle in the international business literature (e.g., Johnson et al., 2006), cultural closeness does not necessarily mean easy cultural adaptation (e.g., Selmer, 2007). As discussed earlier, traditional measures of cultural distance use quantifiable and bipolar cultural values, and do not reflect other differences that may be substantial. China and Japan are similar in terms of a shared Confucian cultural heritage but differ in their economic and political history including phases of capitalism and institutional arrangements (Witt and Redding, 2013), which underscores the importance of a context-specific approach.

\section{Practical Implications}

The message for expatriate managers is that a high level of both Yin and Yang leadership behaviors, or Yin-Yang leadership where there is a balance of Yin and Yang, fosters a high level of employee commitment. As noted earlier, both Yin and Yang coexist in contemporary China, and there is a shifting salience between the two depending on the time, situation and context. Our 
results reveal that a preference for Yang leadership behaviors is salient in contemporary China. Chinese employees prefer a leader that demonstrates strength, clarity, assertiveness, decisiveness, predictive accuracy, and accurate decision making, that is, Yang leadership behaviors. If a leader can show these qualities, local employees of the Chinese subsidiary are likely to be satisfied with the leadership approach and be committed to the organization. Employee commitment is associated with lower employee turnover. This is good news for foreign firms, since the Chinese labor market is fluid with frequent job changes, and there is competition for talent. Our results show that while the Yang component of Yin-Yang leadership has more salience than the Yin component, Yin leadership behaviors are still important. This is underscored in a notable expert observation in the Chinese labor market indicating that for Chinese employees money is a less important reason to change jobs than the potential to grow and have a close working relationship with an immediate boss (Hymowitz, 2005). Relationship development is critically important for Chinese employees, and the majority of Chinese workers seek job opportunities in which they can enhance their employability so as to realize self-fulfilment. This involves both Yin and Yang leadership behaviors.

Employee commitment is a way to capture talent over the long term. Our results suggest that those high-value employees with cosmopolitan values can be retained over the long term with a Yin-Yang leadership approach used by foreign expatriate managers. Such leadership approach addresses the need to placate risk and uncertainty, and to command confidence. A leader that can work well under uncertainty and be assertive in persuading employees with confidence shows his or her followers that they are 'safe' with the company as well as moving forward in a positive manner. This may inspire such talent to remain with the firm. It should be noted that the Yin leadership behaviors of relationship building and benevolence may also be 
appreciated. The results are positive for employee commitment, though less so than managing uncertainty and decisiveness. Collectivistic, harmony-producing Yin leadership behaviors appear to be subsumed by Yang leadership behaviors that address the new economic and institutional order of rapid change and uncertainty. This might be explained by the observation that Chinese society acts as social system where people maintain social order through a harmony-withinhierarchy arrangement (Martinsons, 2006).

Cosmopolitanism appears to be a key to enhancing employee commitment in foreign firms, as well as to navigating the paradoxes inherent in Yin-Yang leadership. Cosmopolitanism has a direct effect on employee commitment. This shows that the more open employees are to new cultures and ways of doing things, the greater the propensity to commit to a foreign firm. At the same time, cosmopolitanism enhances the positive effects of Yin-Yang leadership behaviors on employee commitment. These findings have important recruitment implications for leadership development given the high turnover particularly of top performing employees in China (Nie, 2015) and in many other high-growth Asian countries (Bruning and Tung, 2013).

\section{Research Limitations and Future Directions}

The main limitation of the study is the relatively small sample size. Also, the respondents come from only three Japanese subsidiaries that are located in one region of China where the presence of foreign business activities is highest. Future studies should attempt to gain a larger sample, with more expatriate nationalities represented, and to collect data based also on the geographic segmentation criterion since there is some evidence that leadership preferences may differ across regions in China (Littrell et al., 2012). Geographic segmentation would also be useful to assess the generalizability of cosmopolitanism. Most foreign firms establish and run their branches in 
urbanized areas of China, so people in those areas might be more cosmopolitan, with differential results by region (Ong, 1999; Ralston et al., 1996).

We focused on a few possible predictors of employee commitment in Japanese subsidiaries in China. More work needs to be done to determine other possible factors that could positively influence the attitudes of Chinese employees. Despite these limitations, the study clarified Yin-Yang leadership behaviors that can be adopted by expatriate managers, and the potential role of cosmopolitanism of Chinese employees. The study adds to our knowledge of expatriates' leadership challenges in China and has provided practical guidance.

Future research to test Yin-Yang leadership and cosmopolitanism in foreign firms other than those of Japanese origin is encouraged. Japan and China are often categorized into the same cultural cluster of Confucian Asia, East Asia, or Collectivist in various literatures, thus, arguably, the Yin and Yang dualities of Chinese culture might be better understood by Japanese compared with other foreign MNEs of different cultural clusters. Similarly, the cultural distance between China and Japan is frequently portrayed as small, thus the potential impact of cosmopolitanism in the context of Chinese-Japanese interaction might also be smaller than the context of Chinese and other more culturally distant countries of origin. It would be promising to test if Yin-Yang leadership and cosmopolitan followership lead to a similar positive effect on Chinese employee commitment to foreign firms in general.

Finally, as Yin-Yang leadership is conceptualized to embrace the dualities that pose challenges for foreign firms to operate effectively in the Chinese market, future research in this area will benefit by applying a more complex modeling of yin-yang balancing. In order to observe and test the changing nature of balancing, it is highly desirable to specify the contextual conditions that might require more yang leadership behaviors or yin leadership behaviors. We 
selected the best available existing leadership scales to tap our proposed Yin-Yang leadership

concept, yet we welcome new research that further refines the Yin-Yang leadership concept and

measures.

\section{References}

Agho, A. O., Price, J. L. and Mueller, C. W. (1992), "Discriminant validity of measures of job satisfaction, positive affectivity and negative affectivity". Journal of Occupational and Organizational Psychology, Vol. 65, pp. 185-195.

Barkema, H. G., Chen, X. P., George, G., Luo, Y., \& Tsui, A. S. (2015), "West meets East: New concepts and theories”, Academy of Management Journal, Vol 58 No. 2, pp. 460-479.

Beugelsdijk, S., Kostova, T. and Roth, K. (2017), "An overview of Hofstede-inspired countrylevel culture research in international business since 2006", Journal of International Business Studies, Vol. 48 No.1, pp. 30-47.

Bian, Y. (1994), Work and Inequity in Urban China, State University of New York Press, Albany, NY.

Black, J.S., Gregersen, H.B., Mendenhall, M., and Storh, L.K. (1999), Globalizing People through International Assignments, Prentice Hall, Upper Saddle River, NJ.

Bond, M.H. (1991), Beyond the Chinese face: Insights from Psychology, Oxford University Press, Hong Kong.

Bond, M.H., and Hwang, K. (1986), "The social psychology of Chinese people" in Bond, M.H. (Ed.), The Psychology of the Chinese People, Oxford University Press, Hong Kong, pp. 213266.

Bruning, N.S., and Tung, R.L. (2013), "Leadership development and global talent management in the Asian context: an introduction", Asian Business and Management, Vol. 12, pp. 381386.

Buchanan II, B. (1974), "Building organizational commitment: the socialization of managers in work organizations", Administrative Science Quarterly, Vol. 19, pp. 533-546.

Chen, G.-M. (2002), "Transcending paradox: the Chinese 'middle way' perspective", Asian Pacific Journal of Management, Vol. 19 No. 2/3, pp. 179-199.

Chen, G.-M. (2008), "Bian (Change): a perpetual discourse of I Ching", Intercultural Communication Studies, Vol. 17 No. 4, pp. 7-16.

Chen, M.-J. (2016), “Competitive dynamics: Eastern roots, Western growth", Cross Cultural \& Strategic Management, Vol. 23 No. 4, pp. 510-530.

Chew, I. K. H., \& Putti, J. (1995), "Relationship on work-related values of Singaporean and Japanese managers in Singapore", Human Relations, Vol. 48 No. 10, pp. 1149-1170.

Cook, J. and Wall, T. (1980), "New work attitude measures of trust, organizational commitment and personal need non-fulfillment", Journal of Occupational Psychology, Vol. 54, pp. 221225.

Dickson, M.W., Den Hartog, D.N., and Mitchelson, J.K. (2003), "Research on leadership in a cross-cultural context: making progress, and raising new questions", The Leadership Quarterly, Vol. 14 No. 6, pp. 729-768. 
Dorfman, P. W., Hibino, S., Lee, J.K., Tate, U., and Bautista, A. (1997), "Leadership in Western and Asian countries: commonalities and differences in effective leadership process across cultures", Leadership Quarterly, Vol. 8 No. 3, pp. 233-274.

Fan, P.K., and Zigang, Z.K. (2004), "Cross-cultural challenges when doing business in China", Singapore Management Review, Vol. 26 No. 1, pp. 81-87.

Fang, T. (2005-2006), "From 'onion' to 'ocean': paradox and change in national cultures", International Studies of Management \& Organization, Vol. 35 No. 4, pp. 71-90.

Fang, T. (2012), "Yin-Yang: a new perspective on culture", Management and Organization Review, Vol. 8 No. 1, pp. 25-50.

Fang, T., and Faure, G.O. (2011), "Chinese communication characteristics: a Yin-Yang perspective”, International Journal of Intercultural Relations, Vol. 35, pp. 320-333.

Faure, G.O., and Fang, T. (2008), "Changing Chinese values: keeping up with the paradoxes", International Business Review, Vol. 17, pp. 194-207.

Fukuyama. F. (1996) Trust: The Social Virtues and the Creation of Prosperity, The Free Press, New York, NY.

Gallagher, M. E. (2011), Contagious capitalism: Globalization and the politics of labor in China, Princeton University Press.

Gupta, V., Hanges, P. J., and Dorfman, P. (2002), "Cultural clusters: methodology and findings", Journal of World Business, Vol. 37 No. 1, pp. 11-15.

Hall, E. T. (1976). Beyond culture. New York: Anchor Books/New York University Press

Hofstede, G. (1980). Culture's consequences: International differences in work-related values. Newbury Park, CA: Sage.

House, R.J., Hanges, P.J. Javidan, M., Dorfman, P.W., and Gupta, V. (2004), Culture, Leadership and Organizations: The GLOBE Study of 62 Societies, Sage, Thousand Oaks, CA.

House, R.J. (1971), "A path-goal theory of leader effectiveness", Administrative Science Quarterly, Vol. 16, pp. 321-338.

House, R.J., Wright, N.S., and Aditya, R.N. (1999), “Cross cultural research on organizational leadership: a critical analysis and a proposed theory", in Earley, P.C. and Erez, M. (Eds.), New Perspectives on International Industrial / Organizational Psychology, The New Lexington Press, San Francisco, CA, pp. 535-625.

Hui, C.H., and Tan, C.K. (1996), "Employee motivation and attitudes in the Chinese workforce", in Bond, M.H. (1996), The Handbook of Chinese Psychology, Oxford University Press, Hong Kong, pp. 364-378.

Hwang, K.K. (1987), "Face and favor: the Chinese power game", American Journal of Sociology, Vol. 92, pp. 944-974.

Hymowitz, C. (2005), Recruiting top talent in China takes a boss who likes to coach, Wall Street Journal, http://online.wsj.com/article/0,,SB111447333064516573,00.html (accessed May 7, 2017).

Inglehart, R. and Baker, W. (2000), "Modernization, cultural change, and the persistence of traditional values", American Sociological Review, Vol.65 No.1, pp.19-51.

Javidan, M., Dorfman, P.W., De Luque, M.S., and House, R.J. (2006), "In the eye of the beholder: cross cultural lessons in leadership from Project GLOBE", Academy of Management Perspectives, Vol. 20 No. 1, pp. 67-90.

Jing, R., and Van de Ven, A.H. (2016), "Being versus becoming ontology of paradox management”, Cross Cultural \& Strategic Management, Vol. 23 No. 4, pp. 558-562. 
Johnson, J. P., Lenartowicz, T., \& Apud, S. (2006), “Cross-cultural competence in international business: Toward a definition and a model”, Journal of International Business Studies, Vol. 37 No.4, pp. 525-543.

Kan, M. and Parry, K. W. (2004), "Identifying paradox: A grounded theory of leadership in overcoming resistance to change", Leadership Quarterly, Vol. 15 No. 4, pp. 467-491.

Keller, J., and Lewis, M.W. (2016), "Moving towards a geocentric, polycultural theory of organizational paradox", Cross Cultural \& Strategic Management, Vol. 23 No. 4, pp. 551557.

Kelley, R. E. (2008), "Rethinking followership." The art of followership: How great followers create great leaders and organizations, pp. 5-16.

Kirkman, B. L., Lowe, K. B. and Gibson, C. B. (2006), “A quarter century of culture’s consequences: A review of empirical research incorporating Hofstede's cultural values framework," Journal of International Business Studies, Vol. 37 No. 3, pp. 285-320.

Kogut, B. and Singh, H. (1988), "The effect of national culture on the choice of entry mode", Journal of International Business Studies, Vol. 19 No. 3, pp. 411-432.

Larson, L. L., Hunt, J.G., and Osborn, R.N. (1974), "Correlates of leadership and demographic desirable leadership behaviors: variables in three organizational settings", Journal of Business Research, Vol. 2, pp. 335-47.

Lavine, M. (2014), "Paradoxical leadership and the competing values framework", The Journal of Applied Behavioral Science, Vol. 50 No. 2, pp. 189-205.

Lawrence, P.R. and Lorsch, J.W. (1967), Organizations and Environment: managing differentiation and integration, Homewood, IL: Irwin.

Lee, H-J. (2014), "Identities in the global world of work", in B. Gehrke and M-T. Claes (Eds.), Global Leadership Practices and Cross-cultural Management, Palgrave Macmillan, London, pp. 85-101.

Lee, H-J. (2015), “Cosmopolitanism”, in C.L. Cooper (Ed.), Wiley Encyclopeadia of Management, Volume 6, International Management, Wiley, London, pp. 1-2

Lee, H-J. (2017), “Thinking style across cultures: an interview with Richard Nisbett”, Cross Cultural and Strategic Management, Vol. 24 No. 1, pp. 99-104.

Lee, H-J, Reade, C., Yoshikawa, K., and Arai, R. (2013), "The Confucian Asian cluster? Cultural, economic and institutional explanations of leadership challenges of Japanese managers in China", Association of Japanese Business Studies Annual Conference, July 2013, Istanbul, Turkey.

Lee, Y. T., Han, A. G., Byron, T. K., and Fan, H. X. (2008). Daoist leadership: theory and application. In C. C. Chen and Y. T. Lee (Eds.), "Leadership and management in China: Philosophies, theories, and practices”, pp. 83-107. New York: Cambridge University Press.

Leung, K., and Morris, M. W. (2015). "Values, schemas, and norms in the culture-behavior nexus: A situated dynamics framework", Journal of International Business Studies, Vol. 46 No. 9, pp.1028-1050.

Lewis, M. W. (2000), "Exploring paradox: Toward a more comprehensive guide", Academy of Management review, Vol. 25 No. 4, pp. 760-776.

Li, P.P. (2012), “Toward an integrative framework of indigenous research: the geocentric implications of yin-yang balance", Asia Pacific Journal of Management, Vol. 29, pp. 849872.

Li, P.P. (2014), "The unique value of yin-yang balancing: a critical response", Management and Organization Review, Vol. 10 No. 2, pp. 321-332. 
Li, P.P. (2016), "Global implications of the indigenous epistemological system from the east: how to apply Yin-Yang balancing to paradox management", Cross Cultural \& Strategic Management, Vol. 23 No. 1, pp. 42-77.

Littrell, R.F., Alon, I., and Chan, K.W. (2012), "Regional differences in managerial leader behavior preferences in China", Cross Cultural Management, Vol. 19 No. 3, pp. 315-335.

Littrell, R.F. (2002) "Desirable leadership behaviors of multi-cultural managers in China", Journal of Management Development, Vol. 21 No. 1, pp. 5-74.

Luo, Y., and Zheng, Q. (2016), "Competing in complex cross-cultural world: philosophical insights from Yin-Yang”, Cross-cultural and Strategic Management, Vol. 23 No. 2, pp. 386392.

Martinsons, M.G. (2006), "Comparing the decision styles of American, Chinese and Japanese business leaders", Best Paper Proceedings of the 2006 Academy of Management Annual Meeting, Washington, DC, USA.

Mendenhall, M. E., Osland, J. S., Bird, A., Oddou, G. R., \& Maznevski, M. L. (2008), "Global Leadership: Research. Practice and Development", New York: Routledge.

Mercer HR and Mobility Challenges of Emerging Markets (2011), Mercer Survey Panel, https://www.imercer.com/uploads/Canada/pdfs/CA/HRMobility_Challenges in Emerging Markets TOR.pdf (accessed February 13, 2018).

Meyer, J. and Allen, N. (1997), Commitment in the Workplace. Sage, London.

Meyer, J.P., Srinivas, E.S., Lal, J.B., and Topolyntsky, L. (2007), "Employee commitment and support for an organizational change: test of the three-component model in two cultures", Journal of Occupational and Organizational Psychology, Vol. 80 No. 2, pp. 105-125.

Newburry, W., Gardberg, M.A. and Belkin, L.Y. (2006), "Organizational attractiveness is in the eye of the beholder: The interaction of demographic characteristics with foreignness", Journal of International Business Studies, Vol. 37, pp. 666-686.

Nie, W. (2015), HR challenges: Why one-size-fits-all doesn't work in China, Forbes /Asia http://www.forbes.com/sites/winternie/2015/06/01/hr-challenges-why-one-size-fits-alldoesnt-work-in-china/ (accessed February 13, 2018).

Ong, A. (1999), Flexible Citizenship: The Cultural Logics of Transnationality, Duke University Press, Durham, NC.

Osland, J. and Bird, A. (2000), "Beyond sophisticated stereotyping: Cultural sensemaking in context", Academy of Management Executive, Vol. 14, pp. 65-77.

Pearce, J.L., and Robinson, R. (2000), "Cultivating guanxi as a foreign investor strategy", Business Horizons, Vol. 43, pp. 31-38.

Ralston, D.A, Kai-Cheng, Y., Wang, X., Terpstra, R.H. and Wei, H. (1996), "The cosmopolitan Chinese manager: findings of a study on managerial values across the six regions of China", Journal of International Management, Vol. 2, pp. 79-109.

Reade, C. (2001), "Antecedents of organizational identification in multinational corporations: Fostering identification with the local subsidiary and the global corporation", The International Journal of Human Resource Management, Vol. 12 No. 8, pp. 1269-1291.

Redding, S.G., and Ng, M. (1982), "The role of 'face' in the organizational perceptions of Chinese managers", Organizational Studies, Vol. 3 No. 3, pp. 204-209.

Schad, J., Lewis, M.W., Raisch, S., and Smith, W.K. (2016), "Paradox research in management science: looking back to move forward", The Academy of Management Annals, Vol. 10 No. 1, pp. 5-64. 
Schwartz, S. H. (1999), “A theory of cultural values and some implications for work”, Applied Psychology: An International Review, Vol. 48 No. 1, pp. 23-47.

Schwartz, S. H. (2014), "Rethinking the concept and measurement of societal culture in light of empirical findings”, Journal of Cross Cultural Psychology, Vol. 45 No. 1, pp. 5-13.

Selmer, J. (2007), "Which is easier, adjusting to a similar or to a dissimilar culture?", International Journal of Cross Cultural Management, Vol. 7 No. 2, pp. 185-201.

Smets, M., Jarzabkowski, P., Burke, G.T., Spee, P. (2015), "Reinsurance trading in Lloyd's of London: balancing conflicting-yet-complementary logics in practice", Academy of Management Journal, Vol. 58 No. 3, pp. 932-970.

Smith, W.K., and Lewis, M.W. (2011), "Toward a theory of paradox: a dynamic equilibrium model of organizing", Academy of Management Review, Vol. 36 No. 2, pp. 381-403.

Smith, W.K., Lewis, M.W, and Tushman, M.L. (2016), "Both/and leadership”, Harvard Business Review, May, 2016.

Stahl, G. K., Miska, C., Lee, H-J., and Sully de Luque, M. (2017). The upside of cultural differences: Toward a more balanced treatment of culture in cross-cultural management research. Cross Cultural and Strategic Management, Vol. 24 No.1, pp. 2-12.

Stahl, G. K. and Tung, R. (2015). Toward a more balanced treatment of culture in international business studies: The need for positive cross-cultural scholarship. Journal of International Business Studies, Vol. 46 No. 4, pp.391-414.

Stogdill, R.M. (1963), Manual for the Leader Behavior Description Questionnaire- Form XII An Experimental Revision", Fisher College of Business The Ohio State University, Cincinatti. USA.

Taylor, R. (2005), "China's human resource management strategies: the role of enterprise and government", Asian Business and Management, Vol. 4, pp. 5-21.

Taylor, S., Levy, O., Boyacigiller, N., and Beechler, S. (2008), "Employee commitment in MNCs: impacts of organizational culture, HRM and top management orientations", International Journal of Human Resource Management, Vol. 19 No. 4, pp. 501-27.

The 21 st Century China Research Institution (2011), Directory of Japanese firms in China 201112 (In Japanese), Sososha Ltd, Tokyo.

Tung, R.L. (2008), "The cross-cultural research imperative: the need to balance cross-national and intra-national diversity", Journal of International Business Studies, Vol. 39, pp. 41-46.

Tung, R.L. and Verbeke, A. (2010), "Beyond Hofstede and GLOBE: improving the quality of cross-cultural research", Journal of International Business Studies, Vol. 41, pp. 1259-1274.

Uhl-Bien, M., Riggio, R.E., Lowe, K.B., and Carsten, M.K. (2014), "Followership theory: a review and research agenda", The Leadership Quarterly, Vol. 25, pp. 83-104.

Vroom, V., and Jago, A.G. (1988), The New Leadership: Managing Participation in Organizations, Prentice-Hall, Englewood Cliffs, NJ.

Wang, H., Waldman, D.A., and Zhang, H. (2012), "Strategic leadership across cultures: current findings and future research directions", Journal of World Business, Vol. 47, pp. 571-580.

Warner, M. (2009), “'Making sense' of HRM in China: setting the scene”, The International Journal of Human Resource Management, Vol. 20, pp. 2169-2193.

Witt, M.A. (2010), China: What variety of capitalism? http://www.insead.edu/facultyresearch/research/doc.cfm?did=46188 (accessed February 13, 2018). 
Witt, M. A. and Redding, G. (2013), “Asian business systems: institutional comparison, clusters and implications for varieties of capitalism and business systems theory", Socio-Economic Review, Vol. 11 No. 2, pp. 265-300.

WIR 2017. World investment report 2017: Investment and the digital economy. United Nations, Geneva.

Wong, Y.T., Wong, S.H., and Wong, Y.W. (2010), “A study of subordinate-supervisor guanxi in Chinese joint ventures", The International Journal of Human Resource Management, Vol. 21 No. 12, pp. 2142-2155.

Wu, M., Huang, X., Li, C., and Liu, W. (2012), "How Chinese paternalistic leadership affects subordinates' performance and behavior", Chinese Management Insights, http://www.iacmr.org/V2/Publications/CMI/EH010802_EN.pdf (accessed May 7, 2017)

Wu, W.P. (1994), "Guanxi and its managerial implications for Western firms in China: A case study", study presented at the International Conference on Management Issues for China in the 1990s, University of Cambridge, pp. 23-25.

Wu, W.P. (1996), “Transaction cost, cultural values and Chinese business networks: an integrated approach", study presented at the International Academic Workshop on Chinese Business Connections in Global and Comparative Perspective, Beijing, PRC, pp. 10-12.

Xing, F. (1995), "The Chinese cultural system: implications for cross-cultural management", SAM Advanced Management Journal, Winter, pp. 14-20.

Yeh, R. (1988), “On Hofstede's treatment of Chinese and Japanese values”, Asia Pacific Journal of Management, Vol. 6 No. 1, pp. 149-160.

Zhang, Y., Waldman, D.A., Han, Y.-L., and Li, X.-B. (2015), "Paradoxical leader behaviors in people management: antecedents and consequences", Academy of Management Journal, Vol. 58 No. 2, pp. 538-566.

Zhu, Y., Warner, M., and Rowley, C. (2007), 'Human resource management with 'Asian' characteristics: a hybrid people-management system in East Asia", International Journal of Human Resource Management, Vol. 18, pp. 745-768. 
Table 1. Means, standard deviations, and inter-correlations between the study variables

\begin{tabular}{|c|c|c|c|c|c|c|c|c|c|c|}
\hline Variables & Means & S.D. & 1 & 2 & 3 & 4 & 5 & 6 & 7 & 8 \\
\hline 1. Gender & 1.52 & 0.50 & & & & & & & & \\
\hline 2. Tenure & 3.80 & 3.12 & -.03 & & & & & & & \\
\hline $\begin{array}{l}\text { 3. Employee-Japanese } \\
\text { language proficiency }\end{array}$ & 3.74 & 1.47 & .06 & .15 & & & & & & \\
\hline $\begin{array}{l}\text { 4. Supervisor-Chinese } \\
\text { language proficiency }\end{array}$ & 2.92 & 1.56 & -.08 & -.05 & $-.20^{+}$ & & & & & \\
\hline 5. Job Satisfaction & 3.84 & 0.78 & .14 & .12 & -.07 & $.31^{*}$ & & & & \\
\hline $\begin{array}{l}\text { 6. Yin Leadership } \\
\text { Behaviors }\end{array}$ & 3.99 & 0.62 & -.15 & .15 & .02 & $.22^{*}$ & $.30^{* *}$ & & & \\
\hline $\begin{array}{l}\text { 7. Yang Leadership } \\
\text { Behaviors }\end{array}$ & 3.89 & 0.61 & -.09 & $.24^{*}$ & .10 & .13 & $.46^{* *}$ & $.60^{* *}$ & & \\
\hline 8. Cosmopolitanism & 3.13 & 0.46 & .05 & $.29^{* *}$ & .13 & .07 & .13 & $.28^{* *}$ & .17 & \\
\hline $\begin{array}{l}\text { 9. Organizational } \\
\text { Commitment }\end{array}$ & 3.85 & 0.69 & .03 & .14 & -.02 & .14 & $.41^{* *}$ & $.45^{* *}$ & $.48^{* *}$ & $.24^{*}$ \\
\hline
\end{tabular}


Table 2. Multiple regression results for organizational commitment

\begin{tabular}{|c|c|c|c|c|}
\hline Variables & Model 1 & Model 2 & Model 3 & Model 4 \\
\hline \multicolumn{5}{|l|}{ Controls } \\
\hline Gender & -.02 & .06 & .03 & -.03 \\
\hline Tenure (in years) & .09 & -.00 & .00 & -.06 \\
\hline $\begin{array}{l}\text { Japanese language proficiency } \\
\text { (employee) }\end{array}$ & -.00 & -.06 & -.07 & -.11 \\
\hline $\begin{array}{l}\text { Chinese language proficiency } \\
\text { (supervisor) }\end{array}$ & .02 & -.03 & -.06 & -.06 \\
\hline Job Satisfaction & $.39^{*}$ & $.21^{+}$ & $.21^{+}$ & $.19^{+}$ \\
\hline \multicolumn{5}{|l|}{ Main effects } \\
\hline Yin Leader Behaviors (H1a) & & $.22^{+}$ & .14 & .10 \\
\hline Yang Leader Behaviors (H1b) & & $.25^{*}$ & $.27^{*}$ & $.55^{* * *}$ \\
\hline Cosmopolitanism (H2) & & .12 & .11 & $.25^{*}$ \\
\hline \multicolumn{5}{|l|}{ Two-way interaction effects } \\
\hline Yin-Yang Leadership (H1c) & & & .15 & $.39^{* *}$ \\
\hline Yin x Cosmopolitanism & & & -.14 & -.15 \\
\hline Yang x Cosmopolitanism & & & .22 & .10 \\
\hline \multicolumn{5}{|l|}{ Three-way interaction effects } \\
\hline $\begin{array}{l}\text { Yin-Yang Leadership x } \\
\text { Cosmopolitanism (H3) }\end{array}$ & & & & $-.49^{* * *}$ \\
\hline Change in $R^{2}$ & $.18^{*}$ & $.16^{* * *}$ & $.07^{*}$ & $.08^{* * *}$ \\
\hline$R^{2}$ & .18 & .33 & 40 & .49 \\
\hline Adjusted $R^{2}$ & .13 & .27 & .32 & .40 \\
\hline$F$ & $3.48^{* *}$ & $4.92^{* * *}$ & $4.66^{* * *}$ & $5.88^{* * *}$ \\
\hline
\end{tabular}

Notes. Standardized beta coefficients are reported. For gender, $1=$ male, $2=$ female.

Yin-Yang Leadership: Yin leadership behaviors $\mathrm{x}$ Yang leadership behaviors, Yin-Yang Leadership x Cosmopolitanism: Yin leadership behaviors $\mathrm{x}$ Yang leadership behaviors $\mathrm{x}$ Cosmopolitanism. ${ }^{+} p<.10,{ }^{*} p<.05,{ }^{* *} p<.01,{ }^{* * *} p<.001$. 
Figure 1. Research hypotheses

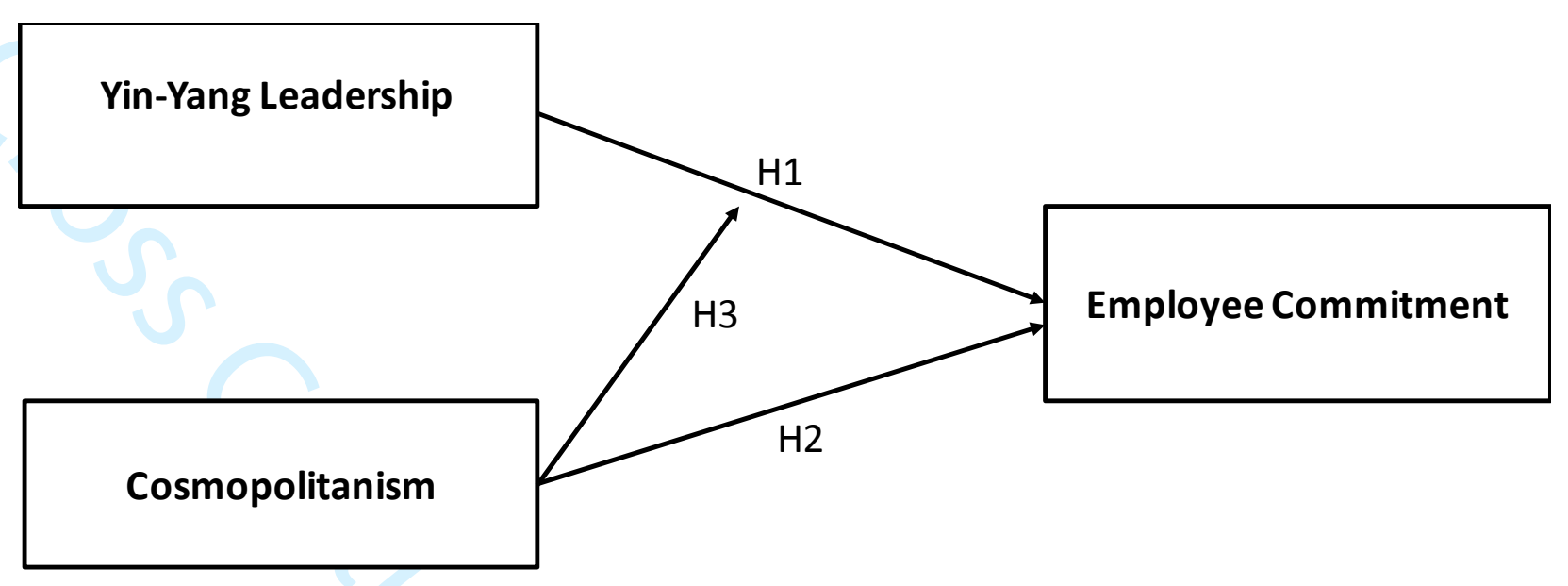




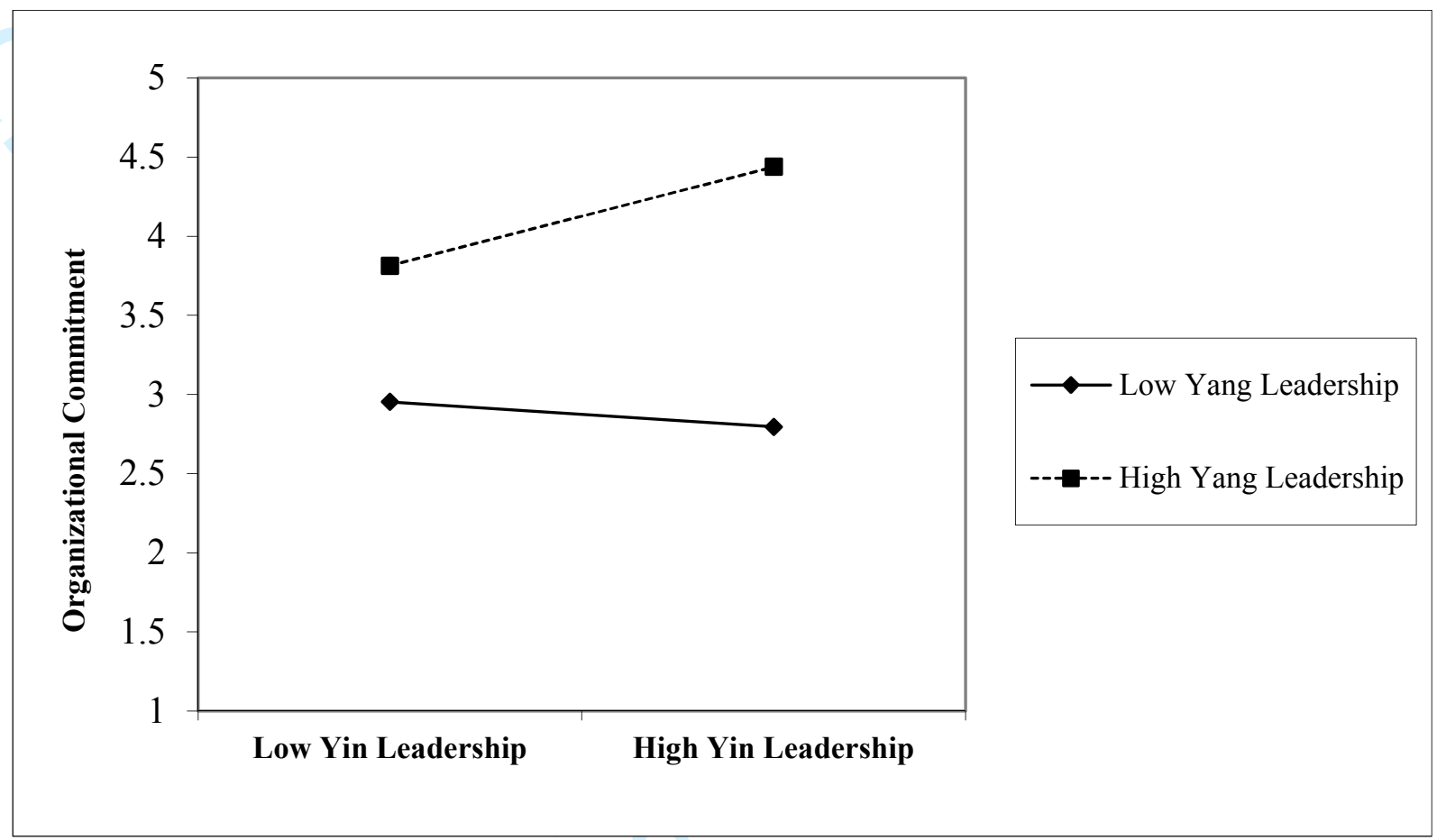

Figure 2. Two-way interaction effects of Yin leadership behaviors and Yang leadership behaviors on employee commitment 


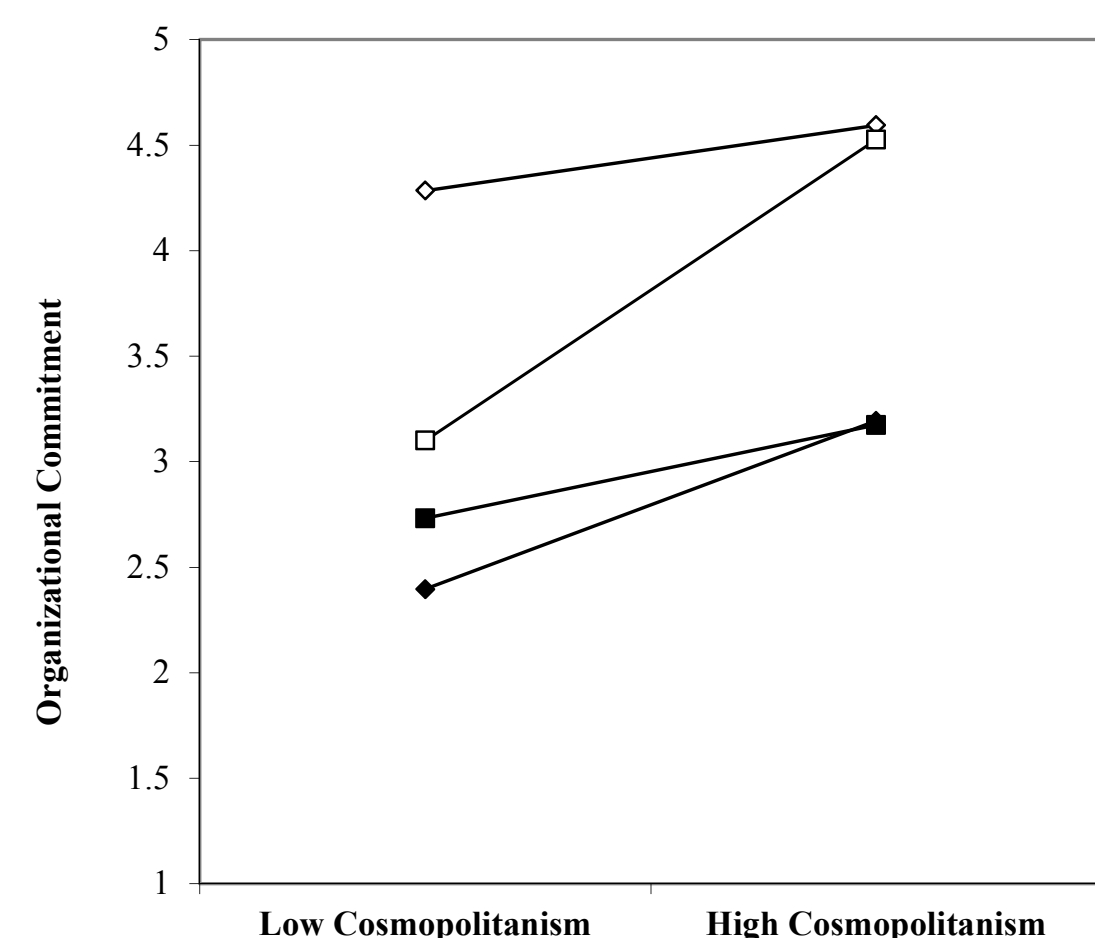

$\neg$ (1) High Yin Leadership, High Yang Leadership

$\multimap$ (2) High Yin Leadership, Low Yang Leadership

$\neg \square$ (3) Low Yin Leadership, High Yang Leadership

$\rightarrow$ (4) Low Yin Leadership, Low Yang Leadership

Figure 3. Three-way interaction effects on employee commitment: Yin leadership behaviors,

Yang leadership behaviors and Cosmopolitanism 